\title{
BMJ Open Cost-effectiveness of integrated COPD care: the RECODE cluster randomised trial
}

Melinde R S Boland, ${ }^{1,2}$ Annemarije L Kruis, ${ }^{3}$ Apostolos Tsiachristas, ${ }^{1,2,4}$ Willem J J Assendelft, ${ }^{5}$ Jacobijn Gussekloo, ${ }^{3}$ Coert M G Blom, ${ }^{6}$ Niels H Chavannes, ${ }^{3}$ Maureen P M H Rutten-van Mölken ${ }^{1,2}$

To cite: Boland MRS, Kruis AL, Tsiachristas A, et al. Cost-effectiveness of integrated COPD care: the RECODE cluster randomised trial. BMJ Open 2015;5: e007284. doi:10.1136/ bmjopen-2014-007284

- Prepublication history and additional material is available. To view please visit the journal (http://dx.doi.org/ 10.1136/bmjopen-2014007284).

Received 24 November 2014 Revised 6 July 2015 Accepted 21 August 2015

CrossMark

For numbered affiliations see end of article.

Correspondence to Dr Melinde RS Boland; boland@bmg.eur.nl

\section{ABSTRACT}

Objectives: To investigate the cost-effectiveness of a chronic obstructive pulmonary disease (COPD) disease management (COPD-DM) programme in primary care, called RECODE, compared to usual care.

Design: A 2-year cluster-randomised controlled trial. Setting: 40 general practices in the western part of the Netherlands.

Participants: 1086 patients with COPD according to GOLD (Global Initiative for COPD) criteria. Exclusion criteria were terminal illness, cognitive impairment, alcohol or drug misuse and inability to fill in Dutch questionnaires. Practices were included if they were willing to create a multidisciplinary COPD team.

Interventions: A multidisciplinary team of caregivers was trained in motivational interviewing, setting up individual care plans, exacerbation management, implementing clinical guidelines and redesigning the care process. In addition, clinical decision-making was supported by feedback reports provided by an ICT programme.

Main outcome measures: We investigated the impact on health outcomes (quality-adjusted life years (QALYs), Clinical COPD Questionnaire, St. George's Respiratory Questionnaire and exacerbations) and costs (healthcare and societal perspective).

Results: The intervention costs were $€ 324$ per patient. Excluding these costs, the intervention group had $€ 584$ (95\% Cl $€ 86$ to $€ 1046)$ higher healthcare costs than did the usual care group and $€ 645(95 \% \mathrm{Cl} € 28$ to $€ 1190)$ higher costs from the societal perspective. Health outcomes were similar in both groups, except for $0.04(95 \% \mathrm{Cl}-0.07$ to -0.01$)$ less QALYs in the intervention group.

Conclusions: This integrated care programme for patients with COPD that mainly included professionally directed interventions was not cost-effective in primary care.

Trial registration number: Netherlands Trial Register NTR2268.

\section{INTRODUCTION}

Disease management programmes for chronic obstructive pulmonary disease

\section{Strengths and limitations of this study}

- It is the largest and most pragmatic Dutch randomised controlled trial to date assessing the cost-effectiveness of a disease management programme for chronic obstructive pulmonary disease patients in primary care.

- The 2-year follow-up period, the broad range of health outcomes and costs (including programme costs) measured and the statistically sophisticated analyses ensure the robustness of the results.

- The uncertainty in the cost-effectiveness of the disease management programmes is adequately estimated and illustrated, enabling the appropriate interpretation of the results.

- The control group was likely to be exposed to quality improvement initiatives as part of usual care.

(hereafter referred to as COPD-DM) have been developed to change COPD care from acute, reactive and one-size-fits-all into integrated, proactive and tailor-made. To stimulate the implementation of such programmes in the Netherlands, a new payment policy (ie, bundled payment) was recently implemented. ${ }^{1}$ However, the wide implementation of these programmes in the Netherlands, as is currently ongoing, would benefit by a justification from a cost-effectiveness perspective.

Recent systematic literature reviews of COPD-DM programmes showed favourable effects on both health outcomes and costs (mainly due to decreased hospitalisation)..$^{23}$ However, previous economic studies had poor methodological quality. ${ }^{2}{ }^{4}$ Most studies did not measure all relevant costs and health outcomes and did not perform incremental cost-effectiveness analyses. ${ }^{2}$ For instance, there is little knowledge on the required investments in implementation of these programmes. Furthermore, the generalisability of the outcomes of these studies was low, due 
to the inclusion of patients with mainly severe COPD and the exclusion of patients with multimorbidity. ${ }^{2} 56$

We aimed to conduct a comprehensive costeffectiveness analysis (CEA) of a COPD-DM programme in primary care compared to usual care in the Netherlands. This CEA was performed as part of a 2-year cluster randomised controlled trial (RCT) evaluating the clinical effects of this RECODE programme (acronym for Randomised clinical trial on Effectiveness of integrated $C O \mathrm{P} D$ management in primary $\operatorname{car} E) .{ }^{78}$

In the clinical paper we concluded that, after 12 months, the RECODE programme did not significantly improve the score on the Clinical COPD Questionnaire (CCQ) compared to usual care, despite an improved level of integrated care and a higher degree of self-reported physical activity. ${ }^{7}$ Our current paper includes additional outcome measures not reported in the clinical paper and it reports 24-month results. This is important because it is often argued that it takes time before the effect of DM programmes becomes clearly visible. The added value of a costeffectiveness analysis is that we report the joint uncertainty in effects and costs, allowing us to report the probability that the RECODE programme would be cost-effective at various threshold values of the maximum acceptable costs per quality-adjusted life year (QALY) gained. Moreover, the publication of results in terms of cost-effectiveness is important to avoid selective reporting of positive studies. The published evidence is used to inform all decisionmakers across developed countries about whether and which COPD-DM programmes to reimburse on a wider scale.

\section{METHODS}

This study was approved by the medical ethics committee, performed according to the study protocol, ${ }^{8}$ as well as national ${ }^{9}$ and international ${ }^{10}$ guidelines for pharmacoeconomic research, and reported according to the Consolidated Health Economic Evaluation Reporting Standard (CHEERS). ${ }^{11}$

\section{Design and intervention}

RECODE is a 2-year cluster randomised trial in which 40 clusters of primary care teams were randomised to the COPD-DM programme or usual care. The 20 teams of the intervention group were trained in essential components of effective COPD-DM: proper diagnosis, optimising medication adherence, motivational interviewing, smoking cessation counselling, applying selfmanagement plans including early recognition and treatment of exacerbations, physical (re)activation and nutritional support. In addition, the teams learnt the details of a web-based computer program for measuring and reporting process and outcome performance indicators, named ZORGDRAAD. This Information and Communications Technologies (ICT) application included a patient and provider portal that facilitated the communication within the multidisciplinary teams as well as between care providers and patients. At the end of the 2-day course, each team developed a plan with steps to be taken in order to redesign the care process and integrate the COPD-DM programme into their daily practice. After the course, the teams were invited to join refresher courses, received regular feedback reports on patients' outcomes and had access to ZORGDRAAD. The local healthcare insurer reimbursed physical reactivation for patients with a Medical Research Council (MRC) dyspnoea score $>2$, and also if these patients had no supplementary insurance. All practices were flexible in determining and following their individual plans. Therefore, the mix and intensity of interventions for individual patients depended on their health status, personal needs and preferences, as well as the actions taken by the team. Healthcare providers in the usual care group were asked to continue providing care as usual. The care as usual has been reported previously. ${ }^{8}$

\section{Target population}

The enrolment of primary care teams and their patients with COPD took place between September 2010 and September 2011. Participating teams included at least one general practitioner (GP), one practice nurse and one physiotherapist. Patients had physiciandiagnosed COPD according to GOLD guidelines. ${ }^{12}$ Exclusion criteria were terminal illnesses, dementia, cognitive impairment, inability to complete questionnaires in Dutch and hard drug or alcohol abuse. Other comorbidity was not an exclusion criterion. The GPs verified that the included patients fulfilled the inclusion and exclusion criteria. All participating GPs and patients with COPD provided written informed consent before participation.

\section{Outcomes}

Costs were related to the following outcome measures:

1. QALYs based on the EuroQol-5D (EQ-5D) utility values using the Dutch value set; ${ }^{13} 14$

2. Proportion of patients with a minimal clinical important difference(MCID) (ie, improvement $\geq 0.4$ ) on the CCQ ${ }^{1516}$

3. Proportion of patients with an MCID (ie, improvement $\geq 4$ ) on St. George's Respiratory Questionnaire (SGRQ); $;^{17} 18$

4. Total number of COPD exacerbations (moderate and severe). A moderate exacerbation was defined as a worsening of daily symptoms that led a patient's clinician to prescribe systemic corticosteroids and/or antibiotics, but did not require hospitalisation. This information was extracted from the Electronic Medical Records (EMR). A severe exacerbation was defined as a worsening of symptoms that required a hospital admission. Hospital admissions were obtained from the resource use questionnaires and the EMR. 
The EQ-5D, CCQ, SGRQ and resource use questionnaires were administered at baseline and at $6,9,12,18$ and 24 months.

\section{Costs}

Total 2-year costs (not only those related to COPD) were calculated from a healthcare perspective and a societal perspective. The healthcare perspective included all costs covered by the healthcare budget, that is, medication prescriptions, contact with care providers (GP, medical specialist, nurse, physiotherapist, dietician, podiatrist, occupational therapist), home care, hospital admissions, emergency department visits and pulmonary rehabilitation. The costs from the societal perspective additionally included travel costs and costs of productivity loss due to absence from paid work.

Patients reported the healthcare utilisation (excluding medication), travel costs, days of absence from paid work due to illness (absenteeism) and lost productivity while being at work (presenteeism) in a resource use questionnaire with a recall period of 3 months.

The medication prescriptions were extracted from the EMRs of the GPs. Standard unit costs were obtained from the Dutch manual for costing research ${ }^{9}$ and inflated to 2013 using the general consumer price index. ${ }^{19}$ The costs of medications were obtained from the GIP-Databank and included value added tax and pharmacist dispensing fees. ${ }^{20}$ The productivity costs were estimated using the Friction Cost Approach, which assumes that productivity loss occurs as long as a sick employee is not replaced (the friction period). ${ }^{21} \mathrm{We}$ used a friction period of 115 days, that is, the average duration of vacancies ( 87 days) increased with the expected number of weeks employers need before taking the decision to place a vacancy for temporary or permanent replacement of the worker (28 days). ${ }^{22}$

The intervention costs, defined as costs of training the teams, costs of the ICT support and costs of the monitoring reports, were calculated on the basis of course attendance (initial 2-day course and refresher courses), computer-documented ICT-use and time involved in producing monitoring reports (for each practice, the estimated labour time was 2.5, 0.5 and $1 \mathrm{~h}$ to produce the reports at baseline and at 6 months and 12 months, respectively).

\section{Statistical analysis}

Data analysis was performed according to the intention-to-treat principle. Data from patients who discontinued the trial prematurely were included in the analysis up to the point of dropout. Additionally, patients who dropped out during the first year were asked to fill in a CCQ questionnaire at 12 months, if possible.

We used repeated measures models to assess differences between RECODE and usual care, correcting for time, age, gender, MRC dyspnoea score $>2$, baseline score and clustering of patients. The distribution and link function for each outcome was selected after comparing the goodness-of-fit of models with different specifications of the distribution and link functions. Models that had the lowest Akaike's Information Criterion were selected.

EQ-5D utilities were analysed using linear mixed models with a normal distribution and identity link. We calculated the number of QALYs for each patient as the area under the predicted utility curve, using linear interpolation between two utility measurements. Generalised linear mixed models with a binary distribution and logit link were used to analyse the proportion of patients with an MCID on the CCQ and SGRQ questionnaires. The differences in exacerbation rates were estimated using generalised linear mixed models with negative binomial distribution and log link. Costs were analysed with generalised linear mixed models using a log-normal distribution and identity link. The cost estimate for months 3-6 (based on the questionnaire administered in month 6) was linearly extrapolated to include months $0-3 .{ }^{23}$ The same was carried out for the cost estimate of months 15-18 and 21-24.

\section{Cost-effectiveness}

Cost-effectiveness was reported in terms of costs per QALY. Additionally, the following incremental costeffectiveness ratios (ICERs) were calculated: costs per additional patient with an MCID on the CCQ costs per additional patient with an MCID on the SGRQ and costs per exacerbation prevented. Taking a multioutcome approach is in line with recent guidelines. ${ }^{24}$

Uncertainty around the ICERs was handled by bootstrapping the data 5000 times. Bootstrapping means repeatedly drawing samples with replacement from the original data set. ${ }^{25}$ Each sample has the same size as the trial and for each sample the difference in costs and QALYs between RECODE and usual care and the ICER is calculated. The 2,5th and the 97,5th centile of the 5000 bootstrap replications form the $95 \%$ uncertainty interval of the differences in costs and QALYs. The 5000 ICERs were plotted on cost-effectiveness planes. ${ }^{26}$ In a cost-effectiveness plane, the horizontal axis displays the difference in effects and the vertical axis displays the difference in costs. The results of the bootstrap replications can fall into one of four quadrants: north-east quadrant (more cost and more effects); south-east quadrant (less cost and more effects); south-west quadrant (less cost and less effects); north-west quadrant (more cost and less effects; see online supplementary appendix 1). Finally, the probability that the RECODE programme is cost-effective using different thresholds for the monetary value of a QALY was shown in cost-effectiveness acceptability curves. ${ }^{27}$ This probability equals the proportion of bootstrap replications in which the ICER is lower than the threshold value.

\section{Sensitivity and subgroup analyses}

Two sensitivity analyses were performed: one with the inclusion of intervention costs and the other with a 
1-year instead of a 2-year time horizon. Five subgroup analyses were performed to study the influence of age, sex, dyspnoea, lung function and socioeconomic status. These were all prespecified in the study protocol and the power calculation was based on the subgroup analyses by MRC dyspnoea score $>2 .{ }^{8}$

\section{RESULTS}

\section{Patients}

The flow chart of patient inclusion has been presented elsewhere. ${ }^{7}$ In total, we included 1086 patients with COPD from 40 teams in the trial, 554 in the RECODE group and 532 in the usual care group. The baseline characteristics of the patients in the RECODE and usual care groups are summarised in table 1 . The only statistically significant difference was a higher percentage of males in the usual care group (51 vs 57\%).

The proportion of patients who completed the trial was $76 \%$ in the RECODE group and $74 \%$ in the usual care group. Length of follow-up among the dropouts was not significantly different between groups, with a mean $( \pm$ sd) follow-up of $20.5( \pm 0.29)$ and $20.0( \pm 0.33)$ months, respectively. Patients who dropped out were significantly older and had a significantly worse baseline score on the CCQ, SGRQ, MRC-dyspnoea and EQ-5D. Baseline characteristics between the dropouts of the

Table 1 Baseline characteristics

\begin{tabular}{|c|c|c|}
\hline & $\begin{array}{l}\text { RECODE } \\
(n=554)\end{array}$ & $\begin{array}{l}\text { Usual care } \\
(n=532)\end{array}$ \\
\hline Age (years), mean (SD) & $68.2 \pm 11.3$ & $68.4 \pm 11.1$ \\
\hline Male sex (\%) & 50.5 & $57.3^{\star}$ \\
\hline Employment (\%) & 27.7 & 28.8 \\
\hline $\begin{array}{l}\text { Low education/low social } \\
\text { economic status (\%) }\end{array}$ & 39.2 & 41.5 \\
\hline Marital status: single (\%) & 37.0 & 38.3 \\
\hline $\mathrm{FEV}_{1} \%$ predicted, mean (SD) & $67.7(20.3)$ & $67.9(20.5)$ \\
\hline Current smoker (\%) & 34.8 & 38.7 \\
\hline Former smoker (\%) & 53.8 & 52.6 \\
\hline $\begin{array}{l}\text { Moderate exacerbation in the } \\
\text { past year, mean (SD) }\end{array}$ & $0.36(0.83)$ & $0.33(0.78)$ \\
\hline $\begin{array}{l}\text { Severe exacerbation in the } \\
\text { past } 3 \text { months, mean (SD) }\end{array}$ & $0.02(0.18)$ & $0.02(0.17)$ \\
\hline Charlson comorbidity index & $2.35(1.26)$ & $2.32(1.27)$ \\
\hline $\begin{array}{l}\text { Major cardiovascular } \\
\text { disease }(\%)\end{array}$ & 14.6 & 17.7 \\
\hline Hypertension (\%) & 35.4 & 38.3 \\
\hline Diabetes (\%) & 14.6 & 14.8 \\
\hline Depression (\%) & 9.8 & 10.1 \\
\hline MRC score, mean (SD) & $2.06(1.30)$ & $1.95(1.26)$ \\
\hline MRC score >2 (\%) & 35.1 & 31.6 \\
\hline CCQ score, mean (SD) & $1.54(0.98)$ & $1.46(0.96)$ \\
\hline SGRQ total score, mean (SD) & $36.7(21.1)$ & $34.5(19.8)$ \\
\hline EQ-5D score, mean (SD) & $0.74(0.25)$ & $0.73(0.28)$ \\
\hline \multicolumn{3}{|c|}{$\begin{array}{l}\text { *Significant }(p<0.05) \text {. } \\
\text { FEV }{ }_{1} \text {, forced expiratory volume in } 1 \mathrm{~s} \text {; MRC, Medical Research } \\
\text { Council; CCQ, Clinical COPD Questionnaire; SGRQ, St. George's } \\
\text { Respiratory Questionnaire;EQ-5D, EuroQoL-5D. }\end{array}$} \\
\hline
\end{tabular}

RECODE group and the usual care group were not significantly different.

\section{Costs}

The intervention costs are presented in table 2. The total intervention costs per patient ranged from $€ 103$ to $€ 587$ across clusters, with a mean ( \pm sd) of $€ 324( \pm 156)$ per patient. This variation is explained by the number of patients with COPD per team, the use of the ICT system, the number of healthcare providers participating in the courses and the different locations of the courses. The labour costs of the attendees of the RECODE courses were the main driver of the intervention costs (54\%).

Complete 2-year medication data of 500 patients (90\%) in the RECODE group and 478 patients (90\%) in the usual care group were extracted from the EMRs. More than $85 \%$ of the participants used medication for obstructive airway diseases in the 2-year trial period (table 3).

Of the 1086 patients, 93\% had complete healthcare utilisation data at 6 months, $79 \%$ at 9 months, $88 \%$ at 12 months, $73 \%$ at 18 months and $75 \%$ at 24 months. This was similar for both groups. The unit costs, observed mean use of resources and associated costs, as reported by the patients, are presented in table 3 . In both groups, important cost drivers were hospital admissions, home care and productivity loss. Excluding intervention costs, the adjusted mean total 2-year costs (estimated from the generalised linear mixed model) were significantly higher in the RECODE group than in the usual care group by $€ 584$ from the healthcare perspective and $€ 645$ from the societal perspective (table 4).

\section{Outcomes}

Over a 2-year period, the number of QALYs was 0.04 ( $p=0.02$ ) lower in the RECODE group than in the usual care group while there was no significant difference in the percentage of patients with an MCID on the CCQ nor in any of the other outcomes (table 4).

\section{Cost-effectiveness}

From a healthcare and societal perspective, the point estimates of costs and effects pointed towards higher costs and lower effects of the RECODE programme, resulting in negative ICERs for all outcome measures (QALYs, exacerbation avoided, additional patient with an MCID on the CCQ score, and additional patient with an MCID on the SGRQ score). The CE planes of the different outcomes showed that the majority of the bootstrap replications $(>98 \%)$ had higher costs. Furthermore, more than half of the bootstrap replications fell within the north-west quadrant of the plane indicating that RECODE was dominated by the usual care group, for example, more costs and less effects.

\section{Sensitivity analyses}

When including the intervention costs, the cost difference, which favoured usual care, further increased to a 
Table 2 Intervention costs (in $€, 2013$ )

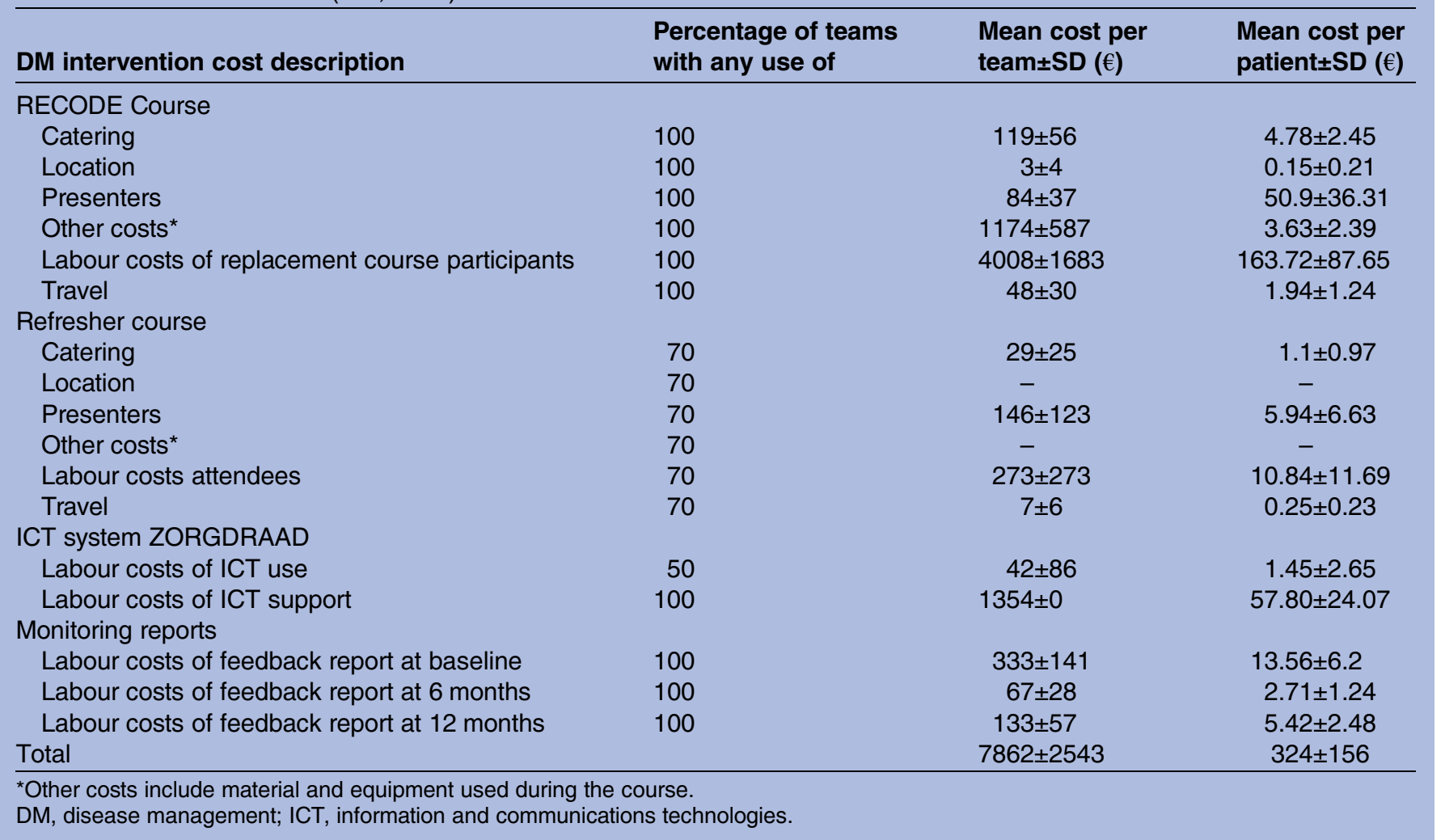

difference of $€ 883$ from the healthcare perspective and $€ 1005$ from the societal perspective (see online supplementary appendix 2).

Using a 12-month instead of a 24-month time horizon, the costs per patient were significantly higher in the RECODE group in comparison with the usual care group by $€ 408$ from the healthcare perspective and $€ 370$ from the societal perspective (see online supplementary appendix 3). After 12 months, there was no significant difference in QALYs, or any of the other outcomes, except for the percentage of patients improving at least the MCID on the CCQ, which was $7 \%$ less in the RECODE group than in the usual care group. After 12 months, the costs per QALY ratio of RECODE compared to usual care was $€ 38471$ from a healthcare perspective and $€ 42458$ from a societal perspective. The probability that RECODE is cost-effective at a willingness-to-pay of $€ 20000$ and $€ 80000$ per QALY at 12 months was $8 \%$ and $79 \%$, respectively (see online supplementary appendix 4). From a societal perspective, these probabilities were slightly higher, that is, $15 \%$ and $81 \%$.

\section{Subgroup analyses}

Only age showed a significant interaction with the effect of RECODE on costs (see online supplementary appendix 5 and 6). The difference in costs (healthcare and societal perspective) between RECODE and usual care was significantly lower in patients younger than 65 years than in patients above 65 years. There was also a significant interaction between age and the effect of RECODE in terms of QALYs. In patients below 65, there was no significant difference in QALYs between RECODE and usual care, whereas in patients 65 or over there were fewer QALYs in RECODE than in usual care (see online supplementary appendix 4). It is more likely that RECODE is cost-effective within the subgroup of patients $<65$ years.

\section{DISCUSSION}

This study compared the costs and health effects of a COPD-DM programme in primary care (RECODE) with usual care in the Netherlands. Our results show that RECODE is not cost-effective from a healthcare as well as a societal perspective. The point estimates of costs and effects pointed towards higher costs and no significant difference in effects, except for 0.04 less QALYs. The majority of bootstrap replications in the CE planes showed that RECODE was dominated by usual care. The decrease in utility, especially in the second year, might be explained by the consistent pattern of no effect or a worse effect on the outcomes. The reduction in utility might also result from the increased awareness by patients of their health problems as an effect of being enrolled in the RECODE programme.

These unexpected findings cannot be related to weaknesses in the research design. The strength of our study lies in the inclusion of a large and representative group of patients with COPD recruited in primary care. 
Table 3 Unit costs, data sources, mean use of resources and associated costs over the 2 years, as reported by the patients (unadjusted)

\begin{tabular}{|c|c|c|c|c|c|c|c|c|}
\hline & \multirow[b]{2}{*}{$\begin{array}{l}\text { Unit } \\
\text { cost }(€)\end{array}$} & \multirow[b]{2}{*}{ Source* } & \multicolumn{3}{|c|}{ RECODE } & \multicolumn{3}{|c|}{ Usual care } \\
\hline & & & $\begin{array}{l}\text { Any } \\
\text { use (\%) }\end{array}$ & $\begin{array}{l}\text { Mean } \\
\text { use }\end{array}$ & $\begin{array}{l}\text { Mean } \\
\text { cost } \pm S D(€)\end{array}$ & $\begin{array}{l}\text { Any } \\
\text { use (\%) }\end{array}$ & $\begin{array}{l}\text { Mean } \\
\text { use }\end{array}$ & $\begin{array}{l}\text { Mean } \\
\text { cost } \pm S D(€)\end{array}$ \\
\hline \multicolumn{9}{|l|}{ Costs from a healthcare perspective } \\
\hline $\begin{array}{l}\text { GP, (home) visits, phone } \\
\text { contacts }\end{array}$ & $15-46$ & a & 91 & 16.23 & $476 \pm 504$ & 89 & 14.02 & $401 \pm 450$ \\
\hline Practice nurse, visits & 23 & b & 74 & 5.51 & $131 \pm 277$ & 75 & 5.18 & $109 \pm 166$ \\
\hline Specialist, visits & 78 & a & 78 & 10.05 & $784 \pm 1037$ & 78 & 9.84 & $768 \pm 973$ \\
\hline Emergency department, visits & 163 & a & 26 & 0.78 & $127 \pm 284$ & 23 & 0.79 & $129 \pm 346$ \\
\hline Physiotherapist, visits & 39 & a & 53 & 25.82 & $1007 \pm 1770$ & 45 & 16.33 & $637 \pm 1260$ \\
\hline Dietician, visits & 29 & a & 21 & 1.45 & $42 \pm 141$ & 19 & 1.21 & $35 \pm 148$ \\
\hline Podiatrist, visits & 32 & $\mathrm{~b}$ & 43 & 3.78 & $121 \pm 203$ & 40 & 3.27 & $105 \pm 167$ \\
\hline Speech therapist, visits & 36 & a & 3 & 0.12 & $4 \pm 42$ & 2 & 0.28 & $10 \pm 158$ \\
\hline Occupational therapy, visits & 24 & a & 4 & 0.29 & $7 \pm 76$ & 3 & 0.32 & $8 \pm 83$ \\
\hline Rehabilitation centre, visits & 78 & a & 12 & 3.86 & $459 \pm 2157$ & 12 & 3.01 & $358 \pm 1731$ \\
\hline $\begin{array}{l}\text { Home care, hours of household } \\
\text { help }\end{array}$ & 26 & a & 22 & 34.42 & $895 \pm 2287$ & 20 & 31.01 & $806 \pm 2171$ \\
\hline $\begin{array}{l}\text { Home care, hours of personal } \\
\text { care }\end{array}$ & 47 & a & 9 & 8.28 & $389 \pm 1995$ & 8 & 9.49 & $446 \pm 2327$ \\
\hline Home care, hours of nursing & 70 & a & 6 & 2.11 & $148 \pm 1108$ & 6 & 2.39 & $167 \pm 1064$ \\
\hline Home care, other, hours & 48 & a & 1 & 0.47 & $22 \pm 262$ & 2 & 0.65 & $31 \pm 309$ \\
\hline Hospital stay, days & 493 & a & 25 & 4.65 & $2293 \pm 5915$ & 25 & 4.84 & $2388 \pm 7522$ \\
\hline Intensive care unit, days & 2356 & a & 5 & 0.49 & $1161 \pm 11316$ & 2 & 0.14 & $328 \pm 2658$ \\
\hline $\begin{array}{l}\text { Drugs for obstructive airway } \\
\text { diseases }\end{array}$ & - & c & 84 & - & $945 \pm 814$ & 84 & - & $934 \pm 1024$ \\
\hline Other medication & - & c & 91 & - & $1367 \pm 3421$ & 90 & - & $1131 \pm 2506$ \\
\hline \multicolumn{9}{|l|}{ Costs from a societal perspective } \\
\hline $\begin{array}{l}\text { Travel expenses, public } \\
\text { transport/car, km }\end{array}$ & 0.22 & a & 94 & 189.00 & $42 \pm 56$ & 92 & 174.43 & $38 \pm 59$ \\
\hline $\begin{array}{l}\text { Productivity loss, absenteeism } \\
\text { hours }\end{array}$ & $31-43$ & a & 11 & 47.74 & $1698 \pm 8344$ & 11 & 42.89 & $1649 \pm 8448$ \\
\hline $\begin{array}{l}\text { Productivity loss, presenteeism } \\
\text { hours }\end{array}$ & $31-43$ & & 8 & 10.38 & $376 \pm 2304$ & 9 & 10.92 & $374 \pm 1774$ \\
\hline
\end{tabular}

*Sources of unit costs used in the analysis: (1) Dutch guidelines for pharmacoeconomic research, ${ }^{9}$ (2) The Dutch Healthcare Authority NZA (3) GIP Databank. ${ }^{20}$

To avoid contamination, randomisation was performed at the cluster level. Since blinding of participants and clinicians was impossible, blinded research nurses collected the data, while patients were instructed not to report back on their type of intervention. Additional strengths of this study are the 2-year follow-up period, the broad range of health outcomes and cost categories included and the sophisticated analyses that took into account the hierarchical nature of the data. A limitation of our study is that we collected healthcare resource utilisation at baseline and at 6,12, 18 and 24 months using a questionnaire with a 3-month recall period, necessitating the extrapolation of the 3-month data to 6 months to estimate the costs of months 3-6, 15-18 and 21-24. We chose to collect intermittent data for two reasons. The first was to avoid study dropouts resulting from endless questionnaires or daily diaries over a long follow-up period. The second reason was that evidence from the literature suggests that intermittent data provide reliable estimates of total annual health expenditures. ${ }^{23}$ A second limitation is that patients who dropped out were significantly older and had a significantly worse baseline score on the CCQ SGRQ MRC-dyspnoea and EQ-5D, thus potentially jeopardising the generalisability of the results. However, baseline characteristics of the dropouts in the RECODE group and the dropouts in the usual care group were not significantly different. Moreover, after correction for baseline scores, no evidence of benefits of the intervention were found, indicating that dropouts are unlikely to have biased the results.

There are several possible explanations for the finding that the RECODE intervention was not cost-effective. First, it may be due to the relatively low intensity of our pragmatic intervention. The RECODE programme did not require the teams to implement all elements of effective COPD-DM that they learnt during the courses. Instead, each team made their own plan to redesign the care process and implement COPD-DM. Consequently, the mixture and intensity of interventions for individual patients was dependent on the health status, personal needs and preferences of the individual patients, as well as on the specific focus that a team may have chosen, 


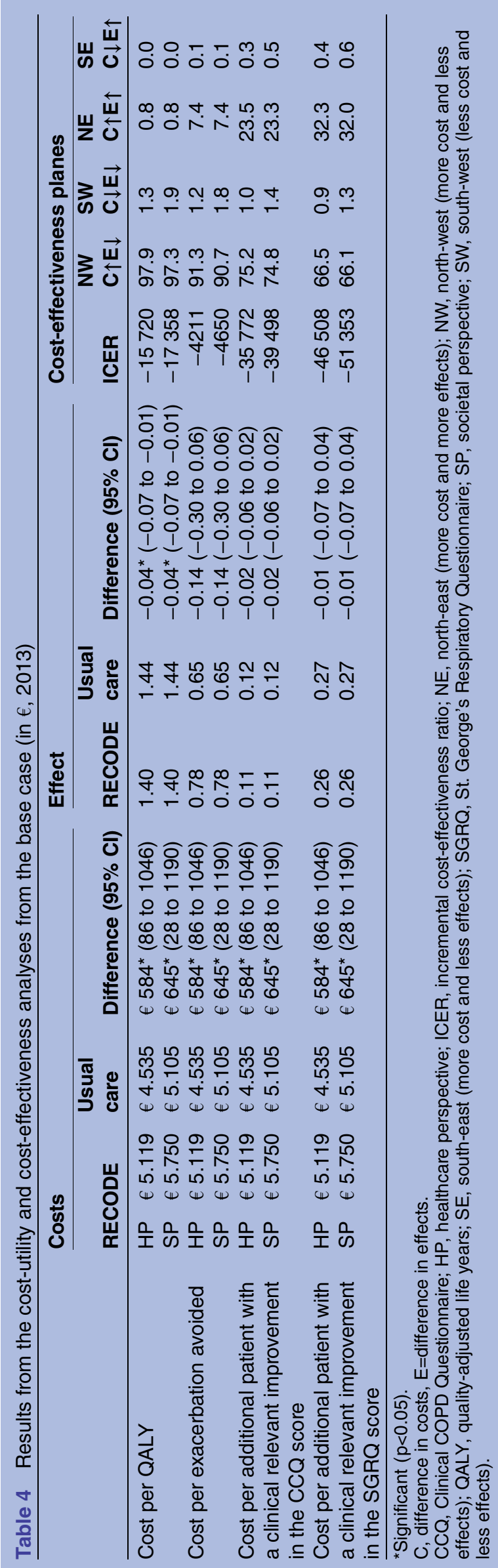

the level of implementation of the DM interventions and the context within which each team operates. As an example of an area that may not have been sufficiently addressed during the courses, we should mention interventions to improve psychological health. ${ }^{28}$ However, only $10 \%$ of the patients in the RECODE trial suffered from a depression at baseline. Although this has probably influenced their motivation to change their health behaviour and may have increased unscheduled care, ${ }^{29}$ it is unlikely to be a major explanation for the lack of effect. Obviously, further research is required to understand the conditions for a successful implementation and thus cost-effectiveness of a COPD-DM programme.

Second, it is questionable whether the pragmatic provider-oriented interventions of the RECODE programme (eg, training and education, support in writing practice reform plans, ICT system Zorgdraad) were optimally translated into patient-oriented interventions. This is important because it has been shown that successful COPD-DM programmes mainly include patient-oriented interventions. $^{2}{ }^{3}$ The literature showed that exercise is an important success factor of a COPD-DM programme and that education, exercise and relaxation are important factors for reducing the use of urgent and unscheduled healthcare among people with COPD. ${ }^{30}$ In our study, physical exercise was not mandatory and only patients with MRC $>2$ received full reimbursement of physiotherapy.

Third, there was limited room for improvement in comparison with previous studies due to the relatively high standard of COPD care in the Netherlands ${ }^{31}$ and the low proportion of patients with severe COPD in this study. $^{2}{ }^{3}$ It could be that a programme like RECODE would have led to more positive results in settings where the COPD care is less advanced. For instance, in 2005, when the standards of good COPD care in developed countries were less well developed, a Spanish study did find that a community-based integrated care programme in frail patients with COPD improved clinical outcomes including survival and decreased the emergency department visits. ${ }^{32}$ Moreover, Bourbeau et a $l^{33}{ }^{34}$ demonstrated positive results of a COPD-DM programme in patients recruited from seven hospitals in Canada in 1999, while a similar programme in 15 general practices in the Netherlands in $2006^{31}$ found no long-term benefits and a study in the USA in 2009 did even find negative results in patients recruited from 20 hospital-based outpatient clinics. ${ }^{35}$ It might well be that as time passes and the quality of COPD care improves, there is less room for improvement. However, even in the presence of incentivised quality improvement programmes like the Quality and Outcome Framework in England, hospital admissions for COPD still occur more frequently among the least well served such as those in deprived areas. ${ }^{36}$ So there is still room for improvement among certain subgroups of patients with COPD and it might be a question of targeting DM programmes at those most likely to benefit. 
Fourth, changes in healthcare occurred during the study period that affected COPD care in the RECODE as well as the usual care group. Since July 2010, a new bundled payment scheme for patients with COPD has been introduced in the Netherlands to stimulate the integration of care ${ }^{37}$ In this scheme, healthcare insurers purchase integrated care from care groups by negotiating a fixed price per patient per year for all multidisciplinary COPD care required by a patient. As the bundle excludes secondary care and medications, it primarily stimulates the cooperation between different providers in the primary care setting. This increased attention for integrated chronic care and the ability to reimburse COPD interventions such as smoking cessation and nutritional counselling could have stimulated integrated care in the usual care group too.

Future research should determine the costeffectiveness of more intensive COPD-DM programmes in primary care using a long(er) time horizon. Hence, the gains from preventing patients with moderate COPD to progress to severe COPD are likely to be detected only in the long run.

In conclusion, this comprehensive economic evaluation of an integrated care programme in primary care showed that the programme increased costs but did not improve health outcomes. It even reduced QALYs. This is most likely due to the suboptimal translation of the provider-oriented interventions of the RECODE programme into patient-oriented interventions, the suboptimal implementation of the interventions, the relatively mild COPD population and the national reforms in COPD care.

\section{Author affiliations}

${ }^{1}$ Institute for Medical Technology Assessment, Erasmus University, Rotterdam, The Netherlands

${ }^{2}$ Institute of Health Policy and Management, Erasmus University, Rotterdam, The Netherlands

${ }^{3}$ Department of Public Health and Primary Care, Leiden University Medical Center, Leiden, The Netherlands

${ }^{4}$ Department of Population Health, Health Economics Research Centre, University of Oxford, Oxford, UK

${ }^{5}$ Department of Primary and Community Care, Radboud University Nijmegen Medical Center, Nijmegen, The Netherlands

${ }^{6}$ Stichting Zorgdraad foundation, Oosterbeek, The Netherlands

Contributors MPMHR-vM, WJJA, JG and NHC conceived and designed the study. MRSB, ALK, AT and CMGB acquired the data. MRSB, AT and MPMHR-v-M analysed and interpreted the data. MRSB drafted the manuscript. ALK, NHC, AT, JG, WJJA and MPMHR-vM advised on the preparation of the manuscript. All authors read, edited and approved the final version of the manuscript.

Funding This paper presents independent research funded by Stichting Achmea Gezondheidszorg, a Dutch Healthcare insurance company and the Netherlands Organisation for Health Research and Development (Zon-MW) (project number 171002203). The funding agencies (Zon-MW and Achmea Zorgverzekeringen) had no influence on the design of the study, the analysis, or the writing of the paper. Throughout the RECODE intervention period, physiotherapists in the intervention group received supplementary funding for providing a COPD specific exercise training programme in patients with MRC scores $>2$. This fund is provided by two local Dutch healthcare insurers: "Centraal Ziekenfonds (CZ) Zorgverzekeringen" and "Zorg en Zekerheid." All other components of the integrated disease management programme were financially covered by the patients' basic insurance scheme.

Competing interests None declared.

\section{Patient consent Obtained.}

Ethics approval The study was reviewed and approved by the medical ethical committee of the Leiden University Medical Centre, the Netherlands.

Provenance and peer review Not commissioned; externally peer reviewed.

Data sharing statement No additional data are available.

Open Access This is an Open Access article distributed in accordance with the Creative Commons Attribution Non Commercial (CC BY-NC 4.0) license, which permits others to distribute, remix, adapt, build upon this work noncommercially, and license their derivative works on different terms, provided the original work is properly cited and the use is non-commercial. See: http:// creativecommons.org/licenses/by-nc/4.0/

\section{REFERENCES}

1. Tsiachristas A, Hipple-Walters B, Lemmens KM, et al. Towards integrated care for chronic conditions: Dutch policy developments to overcome the (financial) barriers. Health Policy 2011;101:122-32.

2. Boland MR, Tsiachristas A, Kruis AL, et al. The health economic impact of disease management programs for COPD: a systematic literature review and meta-analysis. BMC Pulm Med 2013;13:40.

3. Kruis AL, Smidt N, Assendelft WJ, et al. Integrated disease management interventions for patients with chronic obstructive pulmonary disease. Cochrane Database Syst Rev 2013;10: CD009437.

4. Steuten L, Vrijhoef B, Severens $\mathrm{H}$, et al. Are we measuring what matters in health technology assessment of disease management? Systematic literature review. Int J Technol Assess Health Care 2006;22:47-57.

5. Herland K, Akselsen JP, Skjonsberg $\mathrm{OH}$, et al. How representative are clinical study patients with asthma or COPD for a larger "real life" population of patients with obstructive lung disease? Respir Med 2005;99:11-19.

6. Kruis AL, Chavannes NH. Potential benefits of integrated COPD management in primary care. Monaldi Arch Chest Dis 2010;73:130-4.

7. Kruis AL, Boland MR, Assendelft WJ, et al. Effectiveness of integrated disease management for primary care chronic obstructive pulmonary disease patients: results of cluster randomised trial. BMJ 2014;349:95392.

8. Kruis AL, Boland MR, Schoonvelde $\mathrm{CH}$, et al. RECODE: Design and baseline results of a cluster randomized trial on cost-effectiveness of integrated COPD management in primary care. BMC Pulm Med 2013;13:17.

9. Hakkaart-van Roijen L, Tan S, Bouwmans C. Handleiding voor kostenonderzoek, methoden en standaard kostprijzen voor economische evaluaties in de gezondheidszorg. College voor zorgverzekeringen, 2010.

10. Ramsey S, Willke R, Briggs A, et al. Good research practices for cost-effectiveness analysis alongside clinical trials: the ISPOR RCT-CEA Task Force report. Value Health 2005;8:521-33.

11. Husereau D, Drummond M, Petrou S, et al. Consolidated Health Economic Evaluation Reporting Standards (CHEERS) statement. Value Health 2013;16:e1-5.

12. Global Strategy for the Diagnosis, Management and Prevention of COPD. Global Initiative for Chronic Obstructive Lung Disease (GOLD). 2015. http://www.goldcopd.org/

13. Rabin R, de Charro F. EQ-5D: a measure of health status from the EuroQol Group. Ann Med 2001;33:337-43.

14. Lamers LM, McDonnell J, Stalmeier PF, et al. The Dutch tariff: results and arguments for an effective design for national EQ-5D valuation studies. Health Econ 2006;15:1121-32.

15. van der Molen T, Willemse BW, Schokker S, et al. Development validity and responsiveness of the Clinical COPD Questionnaire. Health Qual Life Outcomes 2003;1:13.

16. Kocks JW, Tuinenga MG, Uil SM, et al. Health status measurement in COPD: the minimal clinically important difference of the clinical COPD questionnaire. Respir Res 2006;7:62

17. Jones PW, Quirk FH, Baveystock CM, et al. A self-complete measure of health status for chronic airflow limitation. The St. George's Respiratory Questionnaire. Am Rev Respir Dis 1992;145:1321-7.

18. Jones PW. St. George's Respiratory Questionnaire: MCID. COPD 2005;2:75-9. 
19. CBS Statline. Consumentenprijzen; inflatie vanaf 1963. 2013. http:// statline.cbs.nl/StatWeb/publication/?VW=T\&DM=SLNL\&PA=70936 NED\&D1 =0\&D2=\%28I-34\%29-I\&HD=081020-1258\&HDR= T\&STB=G1 (accessed Apr 2013).

20. College of health insurance (CVZ). GIPdatabank. 2012. http://www. gipdatabank.nl/ (accessed 19 Mar 2012).

21. Koopmanschap MA, Rutten FF, van Ineveld BM, et al. The friction cost method for measuring indirect costs of disease. $J$ Health Econ 1995; $14: 171-89$.

22. Tan SS, Bouwmans CA, Rutten FF, et al. Update of the Dutch manual for costing in economic evaluations. Int $J$ Technol Assess Health Care 2012;28:152-8.

23. Hendriks MR, Al MJ, Bleijlevens $\mathrm{MH}$, et al. Continuous versus intermittent data collection of health care utilization. Med Decis Making 2013;33:998-1008.

24. Cazzola M, MacNee W, Martinez FJ, et al. Outcomes for COPD pharmacological trials: from lung function to biomarkers. Eur Respir J 2008;31:416-69.

25. Briggs $\mathrm{AH}$, Wonderling DE, Mooney CZ. Pulling cost-effectiveness analysis up by its bootstraps: a non-parametric approach to confidence interval estimation. Health Econ 1997;6:327-40.

26. Briggs A, Fenn P. Confidence intervals or surfaces? Uncertainty on the cost-effectiveness plane. Health Econ 1998;7:723-40.

27. van Hout BA, Al MJ, Gordon GS, et al. Costs, effects and C/E-ratios alongside a clinical trial. Health Econ 1994;3:309-19.

28. Panagioti M, Scott C, Blakemore A, et al. Overview of the prevalence, impact, and management of depression and anxiety in chronic obstructive pulmonary disease. Int J Chron Obstruct Pulmon Dis 2014:9:1289-306.

29. Dickens C, Katon W, Blakemore A, et al. Does depression predict the use of urgent and unscheduled care by people with long term conditions? A systematic review with meta-analysis. J Psychosom Res 2012;73:334-42.

30. Dickens C, Katon W, Blakemore A, et al. Complex interventions that reduce urgent care use in COPD: a systematic review with meta-regression. Respir Med 2014;108:426-37.

31. Bischoff EW, Akkermans R, Bourbeau J, et al. Comprehensive self management and routine monitoring in chronic obstructive pulmonary disease patients in general practice: randomised controlled trial. BMJ 2012;345:e7642.

32. Hernández C, Alonso A, Garcia-Aymerich J, et al. Effectiveness of community-based integrated care in frail COPD patients: a randomised controlled trial. NPJ Prim Care Respir Med 2015;25:15022.

33. Bourbeau J, Julien M, Maltais F, et al. Reduction of hospital utilization in patients with chronic obstructive pulmonary disease: a disease-specific self-management intervention. Arch Intern Med 2003;163:585-91.

34. Bourbeau J, Collet JP, Schwartzman K, et al. Economic benefits of self-management education in COPD. Chest 2006;130: 1704-11.

35. Fan VS, Gaziano JM, Lew R, et al. A comprehensive care management program to prevent chronic obstructive pulmonary disease hospitalizations: a randomized, controlled trial. Ann Intern Med 2012;156:673-83.

36. Calderón-Larrañaga A, Carney L, Soljak M, et al. Association of population and primary healthcare factors with hospital admission rates for chronic obstructive pulmonary disease in England: national cross-sectional study. Thorax 2011;66:191-6.

37. Tsiachristas A, Dikkers $\mathrm{C}$, Boland MR, et al. Exploring payment schemes used to promote integrated chronic care in Europe. Health Policy 2013;113:296-304. 